\title{
Mechanistic evidence of enhanced production on artificial reefs: A case study in a Bahamian seagrass ecosystem
}

Craig A. Layman ${ }^{\mathrm{a},}$, Jacob E. Allgeier ${ }^{\mathrm{b}}$, Carmen G. Montaña ${ }^{\mathrm{a}}$

${ }^{a}$ Department of Applied Ecology, North Carolina State University, Raleigh, North Carolina, 27695, USA

${ }^{\mathrm{b}}$ School of Aquatic and Fisheries Science, University of Washington, Seattle, Washington, 98105, USA

*Corresponding author. Tel.: 9195156704

E-mail address: calayman@ncsu.edu 


\begin{abstract}
The attraction-production question, i.e., do artificial reefs support new fish biomass or instead primarily attract fishes from other areas, is one of the most nuanced in coastal marine conservation. Here we provide a novel perspective on this issue, specifically regarding the nutrient dynamics of biogeochemical hotspots that develop following artificial reef construction. Fishes can translocate nutrients (i.e., nitrogen and phosphorus) from the surrounding seascape and concentrate them around artificial reefs, often increasing localized primary production. We discuss an example of this in a seagrass ecosystem, using a case study demonstrating the specific mechanism by which aboveground primary production is enhanced. Namely, when nutrient supply exceeds an ecological threshold, non-linear shifts in nutrient allocation occurs to aboveground tissues, serving to increase localized primary production. Identifying such ecological thresholds in resource allocation provides a powerful predictive tool in the context of fishery management. We suggest that such an ecosystem-level perspective should become more prominent in discussions regarding the attraction-production question of artificial reefs.
\end{abstract}

Key words: biogeochemical hotspot; ecological thresholds; fish excretion; food webs; nutrient capacity; seagrass; secondary production 


\section{Introduction}

Ecological thresholds occur when small changes in an environmental driver produce large changes in ecosystem response, often in non-linear fashion (Groffman et al. 2006). Thresholds are related to specific tipping points at which an environmental driver(s) cause dramatic shifts in community- or ecosystem states (Suding and Hobbs 2009, Kelly et al. 2015). For example, in the Florida Everglades, human activities substantially increase phosphorus loading, the nutrient which is commonly most limiting in this oligotrophic system. When phosphorus levels are above a threshold value, interacting positive feedbacks drive the system away from natural sawgrass (Cladium) prairies to cattail (Typha) dominated marshes. Identifying this nutrient threshold is critical for understanding ecological dynamics, and can serve as a primary target for managing phosphorous loading to the system (Hagerthey et al. 2008). Likewise, there is much potential to use the threshold concept in proactive efforts to reverse environmental deterioration, for example, in restoration efforts (Suding et al. 2004, Suding and Hobbs 2009) or attempts to replenish depleted fishery stocks (McClanahan et al. 2011).

Artificial reefs can be broadly defined as any submerged structures placed on substratum to mimic some characteristics of a natural reef, often to augment fishery yields. Other structures are not designed for this purpose, yet effectively function as artificial reefs, e.g., jetties. Ranging in size from small concrete reef balls to massive offshore oil rigs, these artificial structures can support extremely high densities of fish (Seaman 2000). For example, it was recently suggested that oil and gas platforms off the coast of California have the highest fish production per unit area of any marine habitat worldwide, as much as an order of magnitude higher than other marine ecosystems (Claisse et al. 2014). But a critical question remains regarding the nature of such fish aggregations - to what degree do these fishes represent new biomass/production for 
these systems or, instead, are fish just attracted from other areas (Pickering and Whitmarsh 1997, Seaman 2000, Powers et al. 2003)? If artificial structures do provide for additional fish biomass, this practice could become a core component of fisheries management strategies. But if they primarily serve as fish attractors, artificial reefs may facilitate over-exploitation by making extraction easier for fishers. This "attraction vs. production" question regarding artificial reefs is challenging to resolve for many reasons, one of which is that fundamental ecosystem shifts generated by reef construction are often not well understood (Pickering and Whitmarsh 1997, Seaman 2000, Powers et al. 2003).

Efforts to reconcile this question revolve almost exclusively on the fishery species of interest, e.g., estimating secondary production per unit area on an artificial reef and comparing this to natural habitats (e.g., Claisse et al. 2014). But alternative ecological viewpoints may reveal valuable insights, especially embedding the study of artificial reefs in a more general ecosystem ecology context. For example, deployment of artificial reefs in seagrass beds can result in formation of distinct biogeochemical hotspots in otherwise homogeneous seascapes (Dewsbury and Fourqurean 2010, Allgeier et al. 2013, Layman et al. 2013, Peterson et al. 2013). The main mechanism is translocation and then concentration of nutrients (nitrogen and phosphorus) in a localized area via excretion from aggregated fishes, resulting in a strong bottom-up effect on local ecosystem processes.

Yet this rather general observation leaves much unexplained about specific mechanistic links between fish nutrient supply and seagrass traits. For instance, reef construction seems to initiate a series of positive feedbacks loops, whereby greater seagrass productivity and structural complexity supports higher invertebrate densities, which in turn may feedback to enhance secondary production of fishes (Yeager et al. 2012). Higher fish and invertebrate densities supply 
more nutrients to seagrasses, further increasing seagrass productivity over time. The specific underlying ecological mechanisms by which aboveground primary production is enhanced adjacent to reefs ultimately mediates all of the feedback dynamics. Elucidating these mechanisms would reveal critical aspects of the function of artificial reefs in a broader ecosystem context and provide critical information for their design.

We provide a case study that highlights the need for a broader discussion of artificial reefs in an ecosystem context. Specifically we explored the mechanism by which seagrass production is enhanced around an artificial reef. Theory holds that the relative allocation of resources between above- and belowground seagrass tissues should vary predictably at different levels of nutrient supply (Tilman 1988). We test this assumption by taking advantage of a spatial gradient in nutrient supply, where the highest nutrient cycling rates are immediately adjacent to reefs due to fish aggregating closely to the reef structure (Layman et al. 2013). Two questions framed the research: (1) Are there thresholds at which seagrasses shift resource allocation among tissue structures (blades, roots, rhizomes) across spatial gradients around reefs?; (2) Are aboveground seagrass traits predictable based on biomass and/or nutrient content of belowground structures? We then use these data to discuss how shifts in ecosystem function provide a novel context to evaluate the attraction vs. production question and, more generally, evaluate the efficacy of artificial reefs in enhancing fish production.

\section{Materials and methods}

This case study was based in the Bight of Old Robinson, Abaco, The Bahamas, a semi-enclosed bay that has a complex benthic mosaic comprised predominantly of sand, seagrass (primarily turtle grass Thalassia testudinum), and hard bottom/patch reef habitat. We sampled an artificial 
reef ( $\left.\mathrm{N} 26^{\circ} 20.549^{\prime}, \mathrm{W}^{\circ} 7^{\circ} 00.874^{\prime}\right)$ that had similar spatial patterns in aboveground seagrass traits as other patch reefs (both natural and artificial) in seagrass beds of this area (Allgeier et al. 2013, Layman et al. 2013). This reef (dimensions $\sim 1.2 \mathrm{~m}^{2}$ at base and $\sim 1.2 \mathrm{~m}$ tall) was constructed in March 2009 using 40 cinder blocks arranged in pyramid fashion (Yeager et al. 2011). Samples (December 2013) were taken in spatially-explicit fashion on 3 transects radiating from each reef; transects were oriented $\sim 120^{\circ}$ apart in random directions. Cores were taken with a $12.7 \mathrm{~cm}$ diameter pvc pipe at set distances $(\mathrm{m})$ from the reef on each transect: $1,2,3,4,6,10$, 15,100 . The core was driven $\sim 16 \mathrm{~cm}$ into the sediment and manually excavated, placing one hand under the bottom of the core as it was pulled out. Visual inspection demonstrated cores successfully remove all seagrass tissues from the sampled area. Water was drained from the cores and sand was rinsed off with seawater and then they were placed in individual plastic bags and immediately frozen.

In the laboratory, cores of seagrass biomass were thawed and separated into aboveground biomass (all attached green leaves of shoots) and belowground biomass (rhizomes and roots). Shoots were enumerated and morphology of all blades (length and width) was measured. As a proxy for grazing intensity, we measured the total number of grazing scars on all blades in the core (Valentine and Duffy 2006). Blades were gently scraped with a razor blade to remove epiphytes; belowground material was rinsed with deionized water. Tissues were dried for 72 hours at a constant temperature of $65^{\circ} \mathrm{C}$ and dry weight (to the nearest $0.01 \mathrm{~g}$ ) was recorded. Dried samples were ground into a fine powder using a PRECELLYS ${ }_{24}$ grinder and subsamples of each were analyzed for percent of carbon $(\mathrm{C})$, nitrogen $(\mathrm{N})$, and phosphorous $(\mathrm{P})$. Percent $\mathrm{C}$ and N content were determined using a CHN Carlo-Erba elemental analyzer (Fison NA1500). 
Percent $\mathrm{P}$ was determined by dry oxidation acid hydrolysis extraction followed by colorimetric analysis (Fourqurean et al. 1992).

To explore potential thresholds in allocation of resources between different tissue structures, we first partitioned total plant nutrients into the various tissues from which these measurements were obtained ( $\mathrm{n}=48$ for each tissue type, $\mathrm{n}=144$ total). Partitions included: $\%$ blade nutrients to total (whole-plant) nutrients, \% total belowground (root + rhizome) to total, \% root to total, $\%$ rhizome to total, $\%$ roots to total belowground, and $\%$ rhizome to total belowground. Generalized additive models (gam) were then used to describe the relationship of these data with respect to distance from the reef. If the relationship was non-linear, a changepoint analysis, using the package "changepoint" in R, was used to determine the distance from the reef at which the threshold was reached. Relationships between belowground and aboveground traits were tested using least squares regression. Data were log transformed and satisfied model assumptions.

\section{Results}

Blade length, blade biomass and shoot density were highest adjacent to the reef (Figure 1), consistent with previous aboveground seagrass data from 14 other artificial reefs in this system (Layman et al. 2013). Total root biomass had a similar pattern, but no apparent negative decline was found for rhizome biomass (Figure 1). C, N, and P content decreased for each tissue farther from the reef (Appendix A). Nutrient allocation shifted among different seagrass tissue structures at specific spatial thresholds. Of the 18 nutrient allocation relationships represented in Figure 2, 13 were non-linear. Thresholds were found for $\mathrm{N}$ in all cases, and for $\mathrm{C}$ and $\mathrm{P}$ in 4 and 3 of the scenarios, respectively. Relative nutrient allocation shifted away from blades and roots, and into rhizomes, with increased distance from the reef. Most importantly, allocation shifted 
toward aboveground (relative to total belowground structure) closer to the reef, with this relationship being non-linear for N. In all cases where a threshold was identified, the threshold distance was 7-9 $\mathrm{m}$ from the reef structure. This suggests that this biogeochemical hotspot, i.e., the area over which ecosystem processes were significantly altered by the fish-derived nutrient supply, covered as much as $250 \mathrm{~m}^{2}$ (initiated from a reef with a footprint of only $\sim 1.2 \mathrm{~m}^{2}$ ).

Aboveground seagrass traits were well generally predicted by belowground seagrass traits (total biomass and total percent nutrient content) in 14 of 24 potential models (four of which were only significant at the level of $\alpha<0.1$; Table 1). Surprisingly, belowground biomass did not predict aboveground biomass. However, blade biomass, mean blade height and blade density, were well predicted by the amount of nutrients stored in the root tissue, underscoring the importance of nutrients, as opposed to biomass, for predicting aboveground seagrass traits. The best relationships occurred between total nutrient content in below- and aboveground structures, namely the amount of $\mathrm{P}$ stored in blades. These data suggest aboveground traits are mediated by partitioning of nutrients between above- and belowground structures. In particular, $\mathrm{P}$ appears to be the most critically limiting nutrient for seagrass aboveground production, consistent with previous work within this seagrass bed ecosystem (Allgeier et al. 2011, Allgeier et al. 2013), as well as in other carbonate seagrass systems (Herbert and Fourqurean 2008, 2009, Armitage et al. 2011). There is also evidence of $\mathrm{N}$ in mediating aboveground traits, e.g., the weak relationship between belowground $\% \mathrm{~N}$ and blade height, but the importance of $\mathrm{N}$ appears to be predominantly dependent on availability of $\mathrm{P}$, i.e., relationships with above- and belowground NP molar ratios and above- and belowground traits, suggesting co-limitation of these nutrients (Allgeier et al. 2011). 


\section{Discussion}

Together, these data suggest a mechanism by which seagrass traits are altered by fish aggregations (via their nutrient supply), specifically by allowing for differential allocation of resources among seagrass tissues. In seagrass ecosystems largely devoid of structure, fish densities are relatively low and nutrient supply from their excretion is extremely diffuse across the seascape (Figure 3). At this low level of supply, nutrients taken up by seagrasses are allocated disproportionately to belowground structures. Artificial reefs serve to concentrate fishes in a local patch habitat; many of the fishes remain close to the reef during the day and forage in adjacent seagrass or sand habitats at night, e.g., grunts (Meyer et al. 1983, Yeager et al. 2011), or from the water column, e.g., damselfish (Holbrook et al. 2008). As such, fishes can serve as primary vectors of nutrients, translocating them from adjacent environments (ranging up to distances of $\sim 1-100$ s of meters) to the immediate vicinity of the reef. Our data suggest that there is sufficient nutrient supply from fishes that a critical ecological threshold is reached, at which seagrasses shift a relatively greater proportion of available resources to aboveground structures. A shift in relative resource allocation from below- to aboveground resources is consistent with results from experimental manipulations simulating human-derived nutrient supply in seagrass ecosystems (Armitage et al. 2011), as well as with general theory that nutrient limited plants should invest in belowground structures and nutrient storage but shift to increased leaf area or photosynthetic capacity when nutrient supply is replete (Tilman 1988).

As resources are increasingly allocated to aboveground structures, species interactions and ecosystem processes are shifted in critical ways, apparently initiating self-reinforcing feedback loops. First, increased structural complexity of the seagrass canopy can support higher densities of invertebrates, due to greater availability of food resources, as well as the refugia 
provided from predators (Webster et al. 1998, Yeager et al. 2011). Likewise, seagrasses with higher nutrient content may also attract herbivorous fishes and invertebrates, which may preferentially select higher quality (higher N, P) resources (Heck and Valentine 2006). Our data support this idea of preferential grazing, as scars were more common on high nutrient content blades adjacent to the reef (Figure 1). We note that more attention is needed to the role of grazing in this feedback cycle, as it has been shown to have large influence seagrass structural complexity in some cases (McGlathery 1995, Fourqurean et al. 2010).

Small fishes and invertebrates then provide for a larger forage base for secondary consumers, serving to support higher densities of fishes such as snappers (Lutjanidae) and grunts (Haemulidae) (Yeager et al. 2011, Yeager et al. 2012). Through time, nutrient cycling continues to accelerate as faunal densities increase (Layman et al. 2013), supporting even higher levels of primary production. For example, on the same reef two years prior, thresholds in aboveground seagrass traits were found to be at $\sim 1-4 \mathrm{~m}$ (Layman et al. 2013), whereas thresholds identified in this study (4.5 years after reef construction) were $7-9 \mathrm{~m}$. In essence, the hotspot is expanding in scale over time. This suggests that there are linked spatial and temporal dynamics in this biogeochemical hotspot, with implications for population dynamics, community structure and ecosystem function. Such self-reinforcing positive feedbacks have been termed "whole community mutualisms", and may be much more common than we currently recognize (Bracken et al. 2007).

On artificial reefs, a result of these dynamics may be increased secondary production of economically valuable invertebrates and fishes (Yeager et al. 2012). As such, this ecosystem perspective on the function of artificial reefs reveals insight into the attraction vs. production question that would not be apparent with typical species- or population- level studies. It follows 
that this approach provides an important new insight on artificial reef design, namely, the utility of identifying thresholds in ecosystem processes when choosing where, when, and how reefs should be built. For example, if a reef serves to shift fundamental ecosystem functions by reaching a certain ecological threshold (e.g., as it did for primary production in this case study), it is logical to predict that greater secondary production will also be supported.

Shifts in ecosystem processes associated with artificial reefs is an area of study that warrants a broader synthesis beyond this individual case study. Other studies provide anecdotes of alterations in ecosystem function following reef construction, but this is rarely used as basis for examining the efficacy of reefs for augmenting fisheries production. For instance, similar to the benthic case study described herein, water column phytoplankton production may be concentrated around reefs due altered current flows owing around vertical reef structure (Leitão 2013). Higher water column productivity are utilized by diverse sessile filter-feeders and planktivorous fish, a prey base which can then support higher densities of secondary consumers (Mazzei and Biber 2015). Higher faunal biomass and associated rates of nutrient cycling through pelagic faunal biomass can also result in enhanced organic matter settling to the benthos, fueling accelerated rates of benthic decomposition and remineralization (Falcão et al. 2007, Leitão 2013). Similar processes may occur around other human-made structures that weren't designed as artificial reefs per se. For example, marine aquaculture facilities also can serve as biogeochemical hotspots, with increased localized primary production adjacent to the facilities that is efficiently converted to production of upper trophic level consumers (Machias et al. 2006).

\section{Conclusions}

The ecosystem perspective suggested herein has implications at multiple levels of theoretical and applied ecology. These data provide another example of how non-linearities and ecological 
thresholds may underlie many environmental gradients, and thus are essential to understand in a proactive management context (Kelly et al. 2015). In the case of artificial reefs, ecological thresholds have rarely been explored, limiting our understanding of the ecosystem processes associated with these reef structures. Because of the widespread and ever-expanding scope of artificial reef projects (Ajemian et al. 2015, McLean et al. 2015, Stenberg et al. 2015), more attuned attention to ecosystem function on these structures is clearly needed. Even more broadly, artificial structures (e.g., seawalls, jetties, breakwaters) have become ubiquitous features of the coastal realm, and consideration of their role in fundamentally shifting ecosystem processes should be a primary focus of applied ecological studies in these systems (Bulleri and Chapman 2010).

\title{
ACKNOWLEDGEMENTS
}

NSF OCE \#1405198 to CAL, a NSF Postdoctoral Fellowship in Biology (award \#1402570) to JEA, and North Carolina State provided financial support. Kaye Rennirt assisted with field collections. Olivia Phillips, Aleah Querns, Clara Navarro, and Allison Clonch assisted processing the seagrasses in the laboratory. Many of the images in Figure 3 drawn from the Integration and Application Network, University of Maryland Center for Environmental Science (ian.umces.edu/imagelibrary/).

\begin{abstract}
APPENDIX A
Mean nutrient content of above- and belowground tissues at each sampling distance.
\end{abstract}




\section{LITERATURE CITED}

Ajemian, M. J., J. J. Wetz, B. Shipley-Lozano, and G. W. Stunz. 2015. Rapid assessment of fish communities on submerged oil and gas platform reefs using remotely operated vehicles. Fisheries Research 167:143-155.

Allgeier, J. A., L. A. Yeager, and C. A. Layman. 2013. Consumers regulate nutrient limitation regimes and primary production in seagrass ecosystems. Ecology 94:521-529.

Allgeier, J. E., A. D. Rosemond, and C. A. Layman. 2011. Variation in nutrient limitation and seagrass nutrient content in Bahamian tidal creeks. Journal of Experimental Marine Biology and Ecology 407:330-336.

Armitage, A. R., T. A. Frankovich, and J. W. Fourqurean. 2011. Long-term effects of adding nutrients to an oligotrophic coastal environment. Ecosystems 14:430-444.

Bracken, M. E. S., C. A. Gonzalez-Dorantes, and J. J. Stachowicz. 2007. Whole-community mutualism: associated invertebrates facilitate a dominant habitat-forming seaweed. Ecology 88:2211-2219.

Bulleri, F., and M. G. Chapman. 2010. The introduction of coastal infrastructure as a driver of change in marine environments. Journal of Applied Ecology 47:26-35.

Claisse, J. T., D. J. I. Pondella, M. Love, L. A. Zahna, C. M. Williams, J. P. Williams, and A. S. Bull. 2014. Oil platforms off California are among the most productive marine fish habitats globally. Proceedings of the National Academy of Sciences of the United States of America 111:1546215467.

Dewsbury, B. M., and J. W. Fourqurean. 2010. Artificial reefs concentrate nutrients and alter benthic community structure in an oligotrophic, subtropical, estuary. Bulletin of Marine Science 86:813829.

Falcão, M., M. N. Santos, M. Vicente, and C. C. Monteiro. 2007. Biogeochemical processes and nutrient cycling within an artificial reef off Southern Portugal. Marine Environmental Research 63:429444. 
Fourqurean, J. W., S. Manuel, K. A. Coates, W. J. Kenworthy, and S. R. Smith. 2010. Effects of excluding sea turtle herbivores from a seagrass bed: Overgrazing may have led to loss of seagrass meadows in Bermuda. Marine Ecology Progress Series 419:223-232.

Groffman, P., J. Baron, T. Blett, A. Gold, I. Goodman, L. Gunderson, B. Levinson, M. Palmer, H. Paerl, G. Peterson, N. Poff, D. Rejeski, J. Reynolds, M. Turner, K. Weathers, and J. Wiens. 2006. Ecological thresholds: The key to successful environmental management or an important concept with no practical application? Ecosystems 9:1-13.

Hagerthey, S. E., S. Newman, K. Rutchey, E. P. Smith, and J. Godin. 2008. Multiple regime shifts in a subtropical petland: Community-specific thresholds to eutrophication. Ecological Monographs 78:547-565.

Heck, K. L. J., and J. F. Valentine. 2006. Plant-herbivore interactions in seagrass meadows. Journal of Experimental Marine Biology and Ecology 330:420-436.

Herbert, D. A., and J. W. Fourqurean. 2008. Ecosystem structure and function still altered two decades after short-term fertilization of a seagrass meadow. Ecosystems 11:688-700.

Herbert, D. A., and J. W. Fourqurean. 2009. Phosphorus availability and salinity control productivity and demography of the seagrass Thalassia testudinum in Florida Bay. Estuaries and Coasts 32:188201.

Holbrook, S. J., A. J. Brooks, R. J. Schmitt, and H. L. Stewart. 2008. Effects of sheltering fish on growth of their host corals. Marine Biology 155:521-530.

Kelly, R. P., A. L. Erickson, L. A. Mease, W. Battista, J. N. Kittinger, and R. Fujita. 2015. Embracing thresholds for better environmental management. Philosophical Transactions of the Royal Society B-Biological Sciences 370:20130276.

Layman, C. A., J. A. Allgeier, L. A. Yeager, and E. W. Stoner. 2013. Thresholds of ecosystem response to nutrient enrichment from fish aggregations. Ecology 94:530-536.

Leitão, L. 2013. Artifical reefs: from ecological processes to fishing enhancement tools. Brazilian Journal of Oceanography 61:77-81. 
Machias, A., M. Giannoulaki, S. Somarakis, C. D. Maravelias, C. Neofitou, D. Koutsoubas, K. N. Papadopoulou, and I. Karakassis. 2006. Fish farming effects on local fisheries landings in oligotrophic seas. Aquaculture 261:809-816.

Mazzei, V., and P. Biber. 2015. Autotrophic net productivity patterns at four artificial reef sites in the Mississippi Sound. Hydrobiologia 749:135-154.

McClanahan, T. R., N. A. J. Graham, M. A. MacNeil, N. A. Muthiga, J. E. Cinner, J. H. Bruggemann, and S. K. Wilson. 2011. Critical thresholds and tangible targets for ecosystem-based management of coral reef fisheries. Proceedings of the National Academy of Sciences of the United States of America 108:230-233.

McGlathery, K. J. 1995. Nutrient and grazing influences on a subtropical seagrass community Marine Ecology Progress Series 122:239-252.

McLean, M., E. F. Roseman, J. J. Pritt, G. Kennedy, and B. A. Manny. 2015. Artificial reefs and reef restoration in the Laurentian Great Lakes. Journal of Great Lakes Research 41:1-8.

Meyer, J. L., E. T. Schultz, and G. S. Helfman. 1983. Fish Schools - an Asset to Corals. Science 220:1047-1049.

Peterson, B. J., J. F. Valentine, and K. L. Heck, Jr. 2013. The snapper-grunt pump: Habitat modification and facilitation of the associated benthic plant communities by reef-resident fish. Journal of Experimental Marine Biology and Ecology 441:50-54.

Pickering, H., and D. Whitmarsh. 1997. Artificial reefs and fisheries exploitation: A review of the 'attraction versus production' debate, the influence of design and its significance for policy. Fisheries Research 31:39-59.

Powers, S. P., J. H. Grabowski, C. H. Peterson, and W. J. Lindberg. 2003. Estimating enhancement of fish production by offshore artificial reefs: uncertainty exhibited by divergent scenarios. Marine Ecology-Progress Series 264:265-277.

Seaman, W. S. J. 2000. Artificial reef evaluation with application to natural marine habitats. CRC Press, Boca Raton, FL. 
Stenberg, C., J. G. Stottrup, M. van Deurs, C. W. Berg, G. E. Dinesen, H. Mosegaard, T. M. Grome, and S. B. Leonhard. 2015. Long-term effects of an offshore wind farm in the North Sea on fish communities. Marine Ecology Progress Series 528:257-265.

Suding, K. N., K. Gross, and G. R. Houseman. 2004. Alternative states and positive feedbacks in restoration ecology. Trends in Ecology and Evolution 19:46-53.

Suding, K. N., and R. J. Hobbs. 2009. Threshold models in restoration and conservation: a developing framework. Trends in Ecology and Evolution 24:271-279.

Tilman, D. 1988. Plant strategies and the dynamic structure plant communities. Princeton University Press, Princeton.

Valentine, J., and J. E. Duffy, editors. 2006. The central role of grazing in seagrass ecology. Springer.

Webster, P. J., A. A. Rowden, and M. J. Attrill. 1998. Effect of shoot density on the infaunal macroinvertebrate community within a Zostera marina seagrass bed. Estuarine Coastal and Shelf Science 47:351-357.

Yeager, L. A., C. L. Acevedo, and C. A. Layman. 2012. Effects of seascape context on abundance, condition and secondary production of a coral reef fish, Haemulon plumierii. Marine Ecology Progress Series 462:231-240.

Yeager, L. A., J. A. Allgeier, and C. A. Layman. 2011. Experimental test of the importance of landscape and patch scale variables in predicting fish community assembly. Oecologia 167:157-168. 
Table 1. Results from least squares regression models of belowground characteristics versus aboveground characteristics. The symbol in parentheses indicates the direction of the relationship. NS signifies lack of statistical significance $(\alpha=0.05)$.

\begin{tabular}{|c|c|c|c|c|}
\hline & below biomass & below \%N & below \%P & below NP \\
\hline $\begin{array}{l}\text { blade } \\
\text { biomass }\end{array}$ & NS & NS & $\begin{array}{c}p=0.06, R^{2}=0.38 \\
(+)\end{array}$ & $\begin{array}{c}p=0.04, R^{2}=0.45 \\
(-)\end{array}$ \\
\hline $\begin{array}{l}\text { blade } \\
\text { height }\end{array}$ & $\begin{array}{c}p=0.08, R^{2}=0.34 \\
(+)\end{array}$ & $\begin{array}{c}p=0.06, R^{2}=0.36 \\
(+)\end{array}$ & NS & NS \\
\hline $\begin{array}{l}\text { blade } \\
\text { density }\end{array}$ & NS & $\begin{array}{c}p=0.04, R^{2}=0.43 \\
(+)\end{array}$ & $\begin{array}{c}p=0.02, R^{2}=0.60 \\
(+)\end{array}$ & $\begin{array}{c}p=0.04, R^{2}=0.47 \\
(-)\end{array}$ \\
\hline $\begin{array}{l}\text { blade } \\
\% N\end{array}$ & NS & NS & $p=0.1, R^{2}=0.28$ & NS \\
\hline $\begin{array}{l}\text { blade } \\
\% P\end{array}$ & NS & $\begin{array}{c}p=0.03, R^{2}=0.50 \\
(+)\end{array}$ & $\begin{array}{c}P<0.001, R^{2}=0.84 \\
(+)\end{array}$ & $\begin{array}{c}p<0.01, R^{2}=0.66 \\
(-)\end{array}$ \\
\hline $\begin{array}{l}\text { blade } \\
\text { NP }\end{array}$ & NS & $\begin{array}{c}p=0.08, R^{2}=0.33 \\
(-)\end{array}$ & $\begin{array}{c}p=0.01, R^{2}=0.61 \\
(-)\end{array}$ & $p=0.02, R^{2}=0.59$ \\
\hline
\end{tabular}




\section{FIGURE LEGENDS}

Figure 1. Spatial patterns in seagrass traits surrounding the artificial reef. Means and standard deviations depicted.

Figure 2. Relationships between the relative proportion of total nutrient content for either blade, root or rhizome. Regression lines were generated using generalized additive models using untransformed raw data $(\mathrm{n}=3$ per distance; datapoints in each plot represent the average of these values for visual simplicity). Vertical lines indicate the distance at which an ecological threshold was found. $R^{2}$ indicates the fit of the initial gam model to the data; values are only presented for significant relationships. Points are mean values for each distance.

Figure 3. A conceptual representation of the themes of this study. (A) With little structure, fish are dispersed widely and nutrients, shoot densities are low, and many of the nutrients from fish excretion are allocated belowground. (B) With a small structure, fish aggregate, but their nutrient input is too low to affect aboveground seagrass traits. Some of the additional nutrients may be allocated to belowground structures immediately adjacent to the reef. (C) At a particular level of nutrient supply (because of relatively high fish densities) both above- and belowground seagrass structures are affected. Belowground biomass increases, but disproportionate allocation to aboveground structures results in higher shot densities and blade heights immediately adjacent to the reefs. 
Figure 1
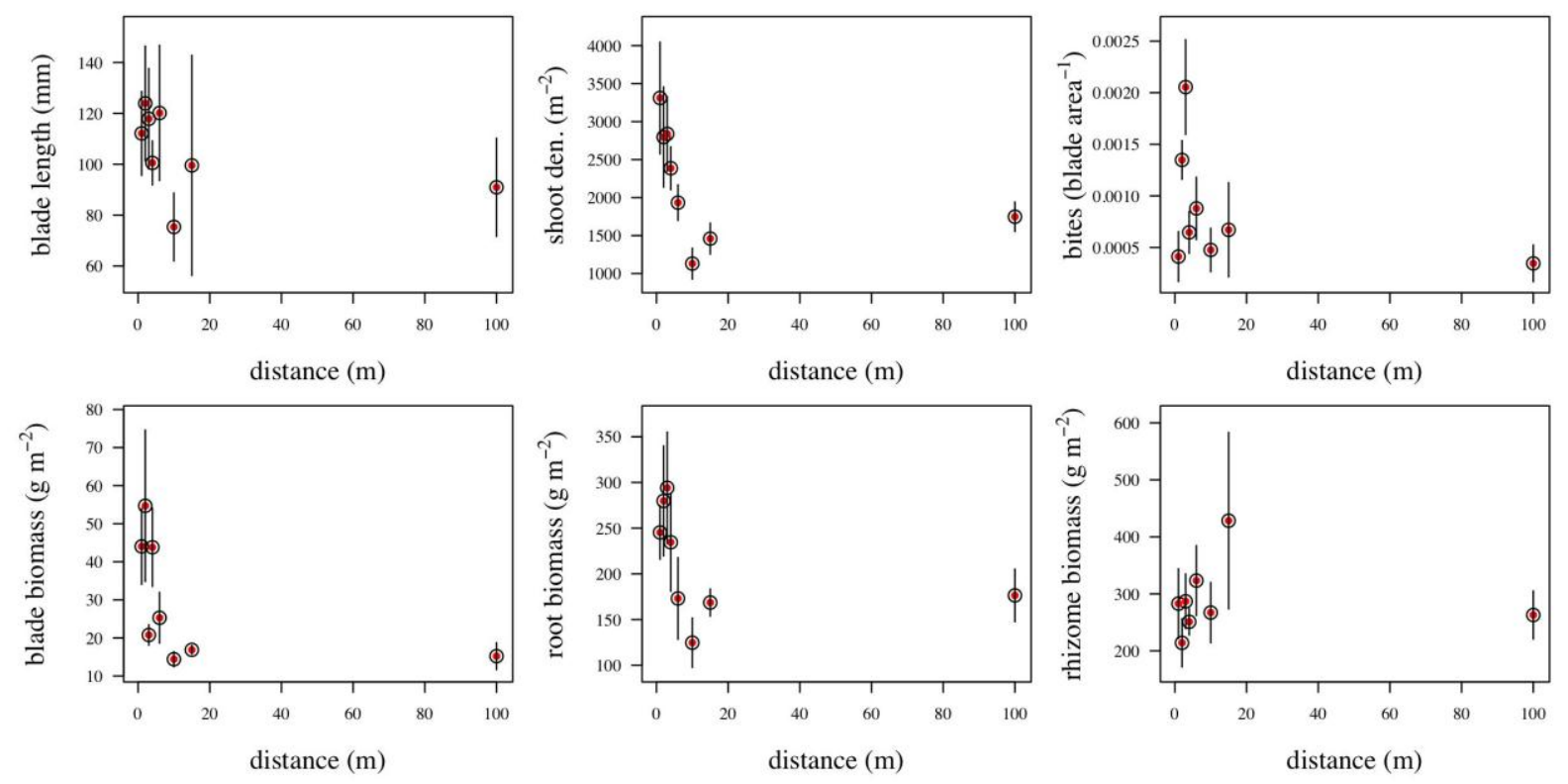
Figure 2
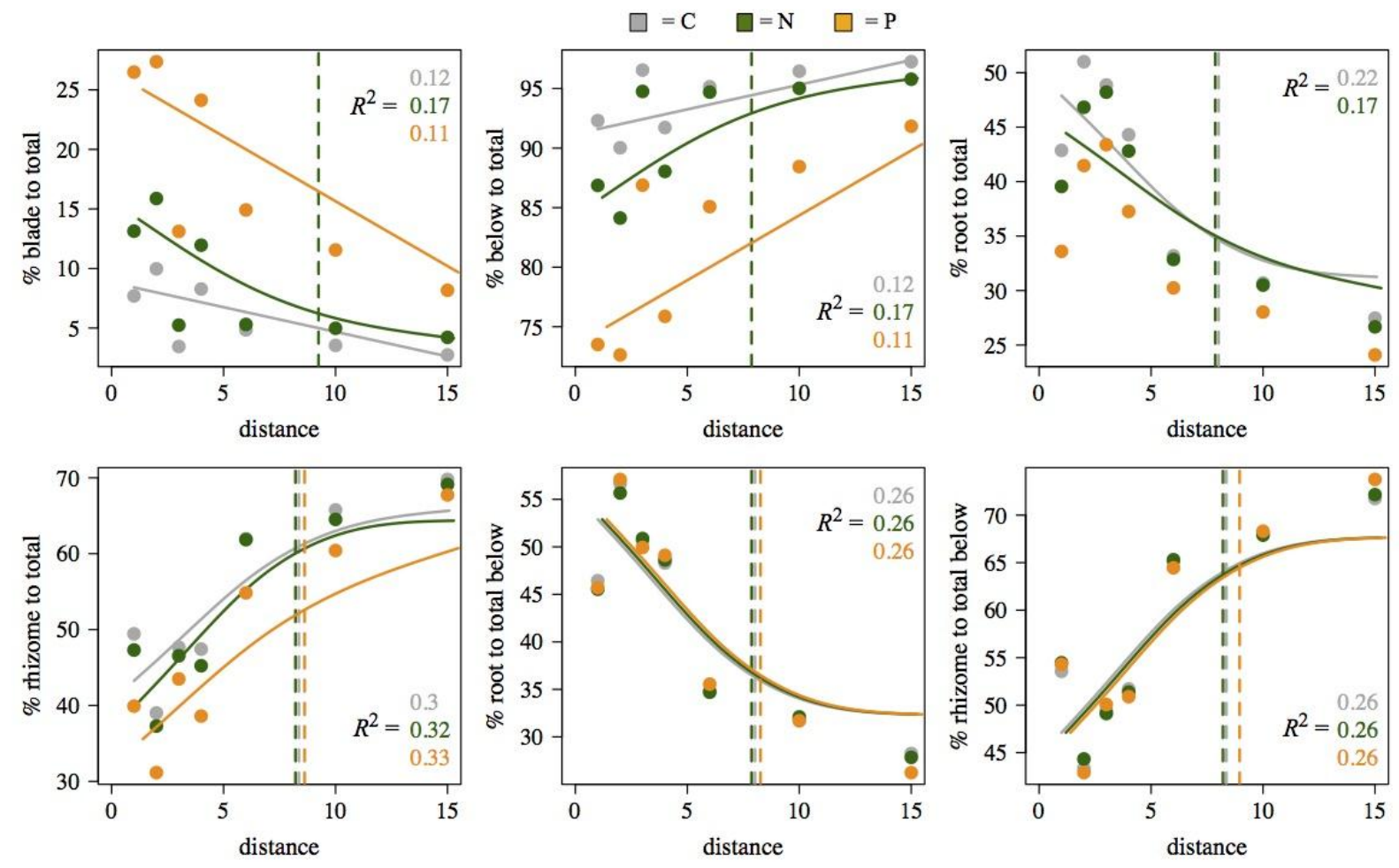
Figure 3

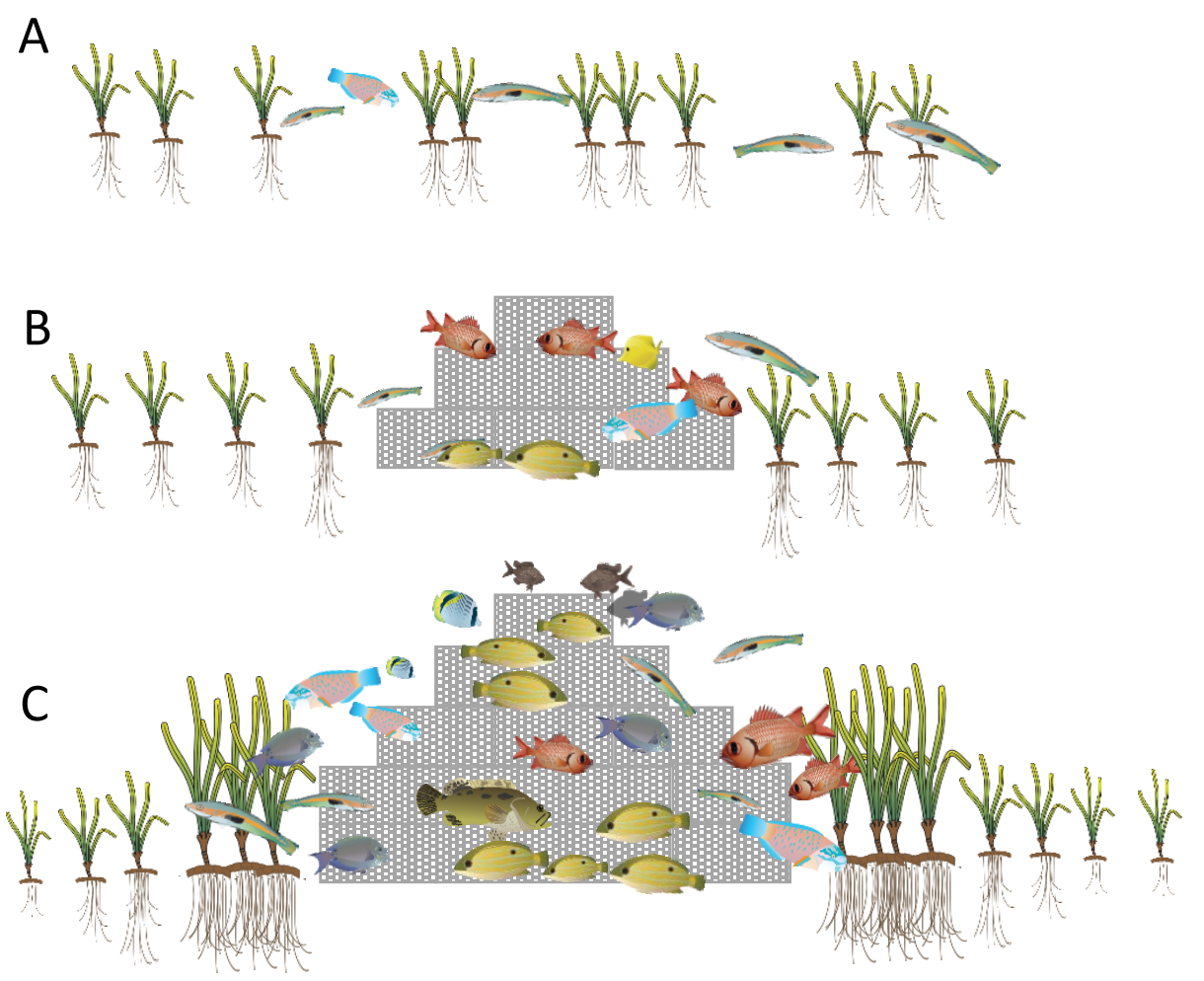

